\title{
TECHNOLOGY OF WINTER CONCRETING OF MONOLITHIC CONSTRUCTIONS WITH APPLICATION OF HEATING CABLE
}

\author{
Antonina Yudina ${ }^{1}$, Rafael Oganyan² \\ 1,2 Saint Petersburg State University of Architecture and Civil Engineering \\ Vtoraja Krasnoarmejskaja ul. 4, St. Petersburg, Russia \\ 11 yudinaantonina2017@mail.ru, ${ }^{2}$ rafaeloganian@mail.ru
}

\begin{abstract}
At the present time, the problem of structure concreting at negative temperatures is particularly sensitive. One of winter concreting methods is electrical heating of structures with the help of heating cable. The paper presents the analysis of existing studies of the concrete curing technology with electric cable upon winter concreting and criteria for selecting the equipment and materials for heating; organizational and technological diagrams were developed for winter concreting of structures with application of concrete heating with electric cable. Recommendations for the selection of heating elements and wiring schemes are given, based on the requirements for improvement of work performance, optimization and rational use of labor and material resources, reduction of time for auxiliary works. Risks, associated with the winter concreting technology with the use of heating cable, were assessed within the framework of the paper.
\end{abstract}

\author{
Keywords \\ Winter concreting, electric curing, heating cable, heating parameters.
}

\section{Introduction}

Today, the high pace of construction is observed in Russia. Construction of buildings from monolithic reinforced concrete constitutes a large part of the industry. This method of construction is popular enough due to the high quality and durability of construction products (Doladov, 2013; Golovnev, 2004; Krasnovsky, 2007).

The production of reinforced concrete structures consists of reinforcement, installation of a formwork and concreting. The preferred option is to make concreting in the warm season. Nevertheless, with account for the geographical setting of Russia and specifics of its climate, a need to perform concrete works at negative temperatures occurs.

Winter concreting requires a number of procedures, which provide organizational and technological aspects to create conditions for concrete maturing at negative temperatures (Golovnev, 1999; Khayutin, 1966).

The relevance of the work is conditioned by the geographical setting and climatic conditions of Russia. Scientific researches of winter concreting were extensively conducted in the USSR; there are numerous publications of modern Russian scientists as well. Soviet scientists developed all possible methods of winter concreting. Great contribution into the study of this construction field was made by B. A. Krylov, S. A. Mironov, A. S. Arbenyev, L. M. Kolchedantsev, A. V. Lagoyda, I. B. Zase- datelev. Achievements of Soviet scientists in particular are confirmed by numerous articles in foreign periodicals and recognition at International meetings.

Nevertheless, with account for numerous fundamental studies on winter concreting, many aspects of this industry remain unconsidered (Krylov, 1975; Mironov, 1975; Molodin, Lunev, 2006).

Discussing this in more detail, we shall note that there is no single way to select the method of winter concreting; there is no principle of determining the actual strength of concrete at its design age; there are problems with measuring temperatures and determining the time of the required concrete mixture curing.

\section{Subject, tasks and methods}

The research subject is the method of concreting with the use of heating cable at negative temperatures.

Main tasks of the research are the following: study of the technology of concrete works performance in winter, analysis of the existing studies in this field, development of a standard scheme for engineering implementation of concreting structures with the electrical heating cable PNSV (heating cable with a steel core and PVC-compound/polyethylene insulation) at negative temperatures (Mosakov, 2006; Pikus, Mozgalev, 2014). 
Methods, which are described in the article, are based on the analysis of the fundamental principles in this field, studies of the Soviet and Russian scientists. As the theoretical basis, scientific publications were taken on the subject of winter concreting and the study of processes occurring in concrete under the effect of various temperatures (Central Research and Design Institute of Organization, Mechanization and Technical Assistance to Construction, 1989; Yudina et al., 2015).

After mixing of cement, the hydration process begins. Cement hydration is a chemical process based on addition of water to clinker components of cement with the formation of new particles. Initially, upon mixing of cement, the cement mortar is obtained; it is gradually thickening and setting, transforming into a solid state, gaining the strength and forming the cement stone. The hydration reaction takes place with the release of heat.

The heat emission of cement upon concrete hardening has both positive and negative sides. The heat source inside the concrete is a positive factor for winter concreting. This allows saving resources upon concrete curing. Curing of concrete in massive structures at negative temperatures may not be carried out, since the exothermic reactions of hardening and insulation covering are enough for maintaining the normal hardening temperature. In thin-walled elements with a large cooling surface module, the supply of external heat is obligatory for winter concreting. Along with this, there is a task to increase the amount of heat released by concrete at hardening. For this purpose, the cement content in winter concrete is increased from 200 up to $400 \mathrm{~kg} / \mathrm{m}^{3}$. This allows for reduction of the curing power and, therefore, costs of winter concreting.

There is a concern about electric energy costs among builders. Winter concreting in modern conditions requires fast, high-quality curing of structures with minimum labor input and small financial investments. The method of winter concreting with the use of heating cable allows for cable laying into the concrete and making maximum use of the produced heat. The curing technology with heating cable provides for application of cables with steel cores, since steel has high electric resistance.

The main issue is the calculation of electric heating parameters. At the present time, there are no regulatory documents for the calculation and technology of concrete curing with heating cable. When developing flow diagrams for winter concreting with the use of heating cable, engineers have only methodical recommendations.

Selection of the heat treatment conditions, ensuring the curing uniformity, calculation of parameters of heating cable and its laying interval require more detailed study. The review of the experience in winter concreting has shown that in most cases concrete curing is performed without preliminary calculations based, in the best case, on the experience of concreting of other structures, and the engineering and technical staff knows little about the specifics of the technique. However, climatic conditions, thickness of structures, electric power capacity, materi- als and equipment are different everywhere, therefore, the heat treatment conditions should be adjusted for each specific case.

The analysis of the heat treatment conditions is based on theoretical calculations of the required amount of heat, measured in $\mathrm{kW}$ of the energy. All calculations are reduced to mathematical expressions and development of alignment charts. At the same time, issues of concrete curing can be referred to the area of the heat-process engineering.

Determination of optimal parameters of the heat treatment conditions is important when preparing the structure curing. Selection of the section area and cable length, as well as the value of the supplied voltage is made by fitting. It is required to set optimal parameters, the most economical option in terms of the minimum labor costs and consumption of material resources.

Control of the concrete temperature constitutes a problem in the issue under consideration as well. Sometimes, the heating temperature is not properly controlled or is not controlled at all at construction sites. This poses a danger of concrete boiling if the heating is too intense or, conversely, there is a lack of the strength at premature power-off.

The method of winter concreting with the use of heating cable needs optimization, improvement and individual approach in the field of organization and development of technologies for various structures.

The method of electric heating is based on the heat release by a high-resistance conductor when the electric current flows through it. A PNSV cable is used as a heating element. This cable consists of a steel core with a PVC-compound covering. Steel cores are manufactured with various diameters; PNSV cables with the core diameter of $1.2,2.0,3.0 \mathrm{~mm}$ are the most commonly used in construction and are available for sale. The larger the diameter, the lower the specific resistance of the conductor. It is recommended in the electric heating technology to calculate the PNSV cable so that the heat release power would be 30-35 $\mathrm{W} / \mathrm{m}$ for reinforced structures and $35-40 \mathrm{~W} / \mathrm{m}$ for u(17 reinforced concrete. The heating power is equal to the electric power of the heating element, since all electrical energy is transformed into the heating energy. The curing power is calculated according to the following equation:

$P=\frac{U^{2}}{R}$

where $P$ is the curing power (W); $U$ is the voltage of a current source $(\mathrm{V}) ; R$ is the resistance of the heating element (Ohm). The curing is carried out with the use of transformers or special stations for concrete curing. Curing stations allow gradual changing of the output voltage. If the supply voltage is $220 \mathrm{~V}$, then the output voltage can be within 35-90 V. The voltage drop 
is necessary to ensure curing safety and reduce the installed length of the heating element.

According to the procedure, the calculation of the installed length of the element is carried out by the following equation:

$$
l=\sqrt{\frac{v^{2} \cdot s}{\rho \cdot \rho_{t}}}
$$

where $I$ is the conductor length $(\mathrm{m}) ; s$ is the area of the core cross-section $\left(\mathrm{mm}^{2}\right) ; p$ is the optimal load per unit length $(\mathrm{W} / \mathrm{m}) ; \rho_{t}$ is the specific core electric resistance at the operational temperature $\left(\mathrm{Ohm} \cdot \mathrm{mm}^{2} / \mathrm{m}\right)$.

It should be noted that the specific resistance of the power core varies with heating, therefore, the total resistance of the core also changes in the heating process. The calculation takes into account the cable resistance at the operational temperature of curing ar(0) corresponding load per the cable unit length. The core resistance, reduced to one running meter of the heating element length at the operational temperature, is calculated by the equation:

$$
R_{t}=\frac{\rho_{t}}{S}
$$

We obtain the following:

$$
l=\sqrt{\frac{v^{2}}{\rho \cdot R_{t}}}
$$

The voltage in heating elements can be changed by switching curing regimes at the concrete curing stations, as well as by changing the corresponding wiring connections. There are 2 wiring diagrams: "triangle" and "star".

In the "triangle" wiring diagram, cables are divided into 3 groups with the same number of cables; cables in a group are connected in parallel. Three sets of cables are tailed to 3 nodes, and their terminations are connected to the output terminals at the transformer substation. Each cable, called a "string" in the group, is powered with linear output voltage of the curing station.

In the "star" wiring diagram, cables are combined in "triples" consisting of 3 equal-length heaters. One end of the cable is fixed to the node, another end of the heater is connected to the output terminals of the curing station. Each cable of the "triple" is under the phase voltage of the transformer, which is 1.73 -fold less than the linear voltage.

The curing technology provides for the use of the PNSV cable which is located directly inside the concrete. The PNSV cable burns out in the open air; therefore, power-on is permitted only after complete installation of the cable into the concrete mixture, when there is no contact between the cable and the air.

When installing the PNSV cable, heating elements are provided with "cold ends" out of the wire APV-4 (aluminum power cable). Using this cable allows fixing the current by rather low heating of "cold ends". Their terminals are connected to the self-supporting insulated wires which serve as mains from transformers to heaters.

The interval of the heater laying is selected according to calculations. As a rule, the interval between PNSV cables is selected as $100-300 \mathrm{~mm}$ in one or two layers. The laying interval is typically multiple of the reinforcement interval for the easy cable installation.

In order to simplify works and reduce the labor intensity, it is recommended to lay cables simultaneously with the installation of the reinforcement. When reinforcing in two layers, the cable should be laid into the structure before the installation of the second layer of reinforcement grids and rods. Damaging of the cable should be avoided during subsequent reinforcement works; cutting and welding of the reinforcement must not be performed over the cable, as there is a risk of damage of insulation and integrity of heating elements.

The cable layout scheme and lengths of segments are accepted for each design structure individually.

Therefore:

- the optimal length of the heater varies from $12 \mathrm{~m}$ up to $83 \mathrm{~m}$, providing a wide choice of wiring schemes and optimization of the cable laying into the concrete structure;

- the thinner the cable section, the shorter the heating element must be in order to meet the requirement for the load per the cable unit length. The selection of the PNSV cable with the diameter of $1.2 \mathrm{~mm}$ should be stipulated not only by its cheapness (the thinner the cable, the cheaper it is), but also by the size of the structure;

- the PNSV cable with the diameter of $1.2 \mathrm{~mm}$ is optimal for wall curing, since the installed length of the cable is limited only by the height of the wall. The cable is laid along the vertical reinforcement rods of the wall forming several kinks. This cable can also be used for heating of relatively short structures $(16.5 \mathrm{~m}$ long when connected in the "triangle" scheme and $19 \mathrm{~m}$ long when connected in the "star" scheme);

- the PNSV cable with the diameter of $3 \mathrm{~mm}$ has the largest installed length due to low specific resistance of the cable. This type of cable can be applied as a heater for large areas of a heated structure. If there are large blocks of concreting, the use of this cable is often the only possible solution, since it allows covering large heating areas with a single power connection point (41 $\mathrm{m}$, when connected in the "triangle" scheme, and $47 \mathrm{~m}$ when connected in the "star" scheme);

- in case of small-sized structures or small sections of concrete walls, ceilings, columns, beams and sites, the larger installed length of the PNSV cable with the 
diameter of $3.0 \mathrm{~mm}$ at the same power capacity conditions an increase in the number of kinks and, consequently, more uniform heating of the concrete, however, it increases the labor intensity of the cable laying. The use of long heaters reduces the number of terminations and installation cables laid from heating elements to transformer substations, resulting in certain cost savings. If a cable is damaged, a significant area of the concrete structure is deprived of curing, and that can cause uneven deformations and/or freezing of the concrete;

- the PNSV cable with the diameter of $2.0 \mathrm{~mm}$ is an intermediate option combining advantages and disadvantages of cables with the diameter of 1.2 and $3.0 \mathrm{~mm}$;

- the "star" wiring scheme allows 1.73-fold reduction of the conductor length. This scheme is recommended to be applied only for curing floorings due to wiring specifics. If the length of the heated structure is equal to the length of the heating element, no arrangement of kinks is required. Absence of kinks reduces the labor intensity, however, the use of short heaters increases the number of outputs and end connections to terminals of the transformer substation. In case of accidental failure or burnout of a cable, one string of the heating element drops out of the whole wiring circuit, while the others continue to work. The structure section in the failure zone ceases to receive the heat from the open cable, but the heat from adjacent heaters will prevent the structure from freezing;

- selection of the supply voltage depends on the conductor length and the heating station type. The longer the length, the higher the voltage for the given power capacity would be. However, the increase in the concrete temperature and, therefore, the voltage should occur gradually (usually stepwise), for example, using successive stages of $35 \mathrm{~V}, 45 \mathrm{~V}$ and $60 \mathrm{~V}$, which would ensure smooth reaching of the designed capacity, which is provided at $60 \mathrm{~V}$ during the required period;

- the total concrete curing capacity provided with the PNSV heaters in $\mathrm{kW}$ determines the selection of the equipment (concrete curing stations, transformers). The analysis of the market of modern curing stations has shown that concrete curing stations manufactured by ETA company are the most common in sale and at construction sites in Saint Petersburg. In particular, these are $\mathrm{SPb}-100, \mathrm{SPb}-80, \mathrm{SPb}-63, \mathrm{SPb}-40$, and SPb-20 stations. This equipment allows industrial-scale concrete curing in monolithic structures in winter.

KTPTO-80 substations and their various modifications are also common, but to a slightly lesser extent. Concrete works in winter are based on the use of the above equipment. If production capacities are smaller, other voltage transformers, which are not specialized equipment, can be used.

\section{Results and discussion}

Advantages and disadvantages of the winter concreting technology were revealed in the course of the carried out study. The method of the electric curing with the application of the PNSV heating cable in concreting of thin-walled constructions was considered in detail. The review of the existing recommendations, methods of calculation and scientific publications on the stated subject was carried out. Obvious advantages of the method are the following: location of heaters in the concrete of structures; acceleration of the concrete strengthening due to high temperatures; relative uniformity of structure curing in comparison with other methods of winter concreting; ability to perform curing immediately after mixture placing; availability of the regime adjustment during the concrete temperature treatment. Disadvantages of the method are the following: the lack of a unified procedure for calculating curing parameters; approximate evaluation of the temperature distribution in the concrete and the required heating power with the help of mathematical calculations; complexity of installation of electric heaters; uniformity of the existing approaches to implementation of wiring schemes without the cost optimization.

\section{Conclusion}

1. Analysis of the theory and practice of winter concreting of monolithic structures with the use of heating cable showed the need of optimization and improvement of the method and introduction of new technologies.

2. Publications and practical methods on the stated subject were studied. Modern methodological recommendations do not have a unified calculation procedure for the required curing power capacity. Manual calculations based on the procedures are approximate and can serve only for approximate choice of the optimal cable laying interval and heat supply. The evaluation of the parameters of electric curing does not take into account all affecting factors, such as the intensity of the hydration reaction in dependence on the time and temperature, unevenness of heat losses in the structure, and changes in characteristics of the concrete in the process of its curing.

3. By the example of the considered curing of the concrete flooring it was noted that attention should be paid to the stress-strain state of the concrete during execution of works. The presence of thermal expansions and shrinkages implies the risk of crack formation. Particular attention should be paid to concreting at reconstruction sites, since there is a risk of cracking in concrete elements upon intensive curing of the concrete and limitation of possible strains.

4. The review of the regulatory documentation on temperature control of concrete at curing was carried out. Temperature monitoring should be carried out with the use of modern monitoring tools based on the principles of automation and independence to ensure the product quality.

5. Practical recommendations for the selection of the organizational and technological scheme of winter 
concreting with the use of heating cables were given. When selecting the wiring scheme, the length and the section of a heater based on the PNSV cable and the concrete curing station, the individual approach is required for each structure, with account for convenience of the installation and the compliance with the concrete heat treatment conditions in accordance with these recommendations. Influence of geometric dimensions of the structure on the choice of the scheme and PNSV cables is shown. The possibility of the method optimization on the basis of increase in labor capacity upon selection of optimal lengths of heaters, the wiring scheme and heating organization is proved.
6. The need to eliminate the risk of cable failure with the help of careful checking of the integrity and quality of cable laying was revealed, in order to prevent temperature changes and freezing of the structure in different parts.

7. Particular attention should be paid to the arrangement of quality control during critical operations; this control should be based on the monitoring of heat and moisture regimes, use of high-quality materials, and compliance with the production procedures and control of the concrete strength. 


\section{References}

Doladov, Y.I. (2013). Progrev betona greiushchim provodom v usloviiakh rekonstruktcii obekta [Concrete heating with heating cable during reconstruction of an object]. In: Proceedings of the 71st All-Russian Scientific and Technical Conference "Traditions and innovations in construction and architecture". Samara, pp. 922-923. (in Russian)

Golovnev, S.G. (2004). Tekhnologiia zimnego betonirovaniia [Technology of concrete works in winter]. Chelyabinsk: Publishing House of the South Ural State University, p.70. (in Russian)

Golovnev, S.G. (1999). Tekhnologiia betonnykh rabot v zimnee vremia [Optimization of parameters and selection of methods]. Chelyabinsk: Publishing House of the South Ural State University, p.156. (in Russian)

Khayutin, Y.G. (1966). Monolitnyi beton [Monolithic concrete]. Moscow: Stroyizdat, p.175. (in Russian)

Krasnovsky, B.M. (2007). Inzhenerno-fizicheskie osnovy metodov zimnego betonirovaniia [Engineering and physical foundations of winter concreting methods]. Moscow: Publishing House of the State Academy for Specialists in Investment Sphere, p.512. (in Russian)

Krylov, B.A. (1975). Elektroprogrev i elektroobogrev betona [Electric heating of concrete]. Moscow: Stroyizdat, p.264. (in Russian)

Mironov, S.A. (1975). Teoriia i metody zimnego betonirovaniia [Theory and methods of winter concreting]. Moscow: Stroyizdat, p.700. (in Russian)

Molodin, V.V., Lunev, Y.V. (2006). Betonirovanie monolitnykh stroitelnykh konstruktcii v zimnikh usloviiakh [Concreting of monolithic building structures in winter]. Novosibirsk: Novosibirsk State University of Architecture and Civil Engineering (Sibstrin), p.300. (in Russian)

Mosakov, B.S. (2006). Tekhnologiia zimnego betonirovaniia: uchebnoe posobie [Technology of winter concreting: textbook]. Novosibirsk: Publishing house of the Siberian Transport University, p.144. (in Russian)

Pikus, G.A., Mozgalev, K.M. (2014). Otcenka neobkhodimogo kolichestva kontrolnykh temperaturnykh tochek pri vyderzhivanii monolitnykh plitnykh konstruktcii $v$ zimnee vremia [Estimation of the necessary number of control temperature points during aging of monolithic raft constructions in winter]. Academic Bulletin of UralNIlproekt of the Russian Academy of Architecture and Construction Sciences, 3, pp.70-71. (in Russian)

Central Research and Design Institute of Organization, Mechanization and Technical Assistance to Construction (TSNIIOMTP) (1989). Recommendations on electric heating of monolithic concrete and reinforced concrete with heating cables. Moscow: Publishing House of TSNIIOMTP, p.67. (in Russian)

Yudina, A.F., Verstov, V.V., Badyin, G.M. (2015). Tekhnologicheskie protcessy $v$ stroitelstve [Engineering processes in construction]. Moscow: Publishing Center "Academy", p.304. (in Russian) 